\title{
Risk assessment of genetically engineered crops: fitness effects of virus-resistance transgenes in wild Cucurbita pepo
}

\author{
Karen D. Laughlin, ${ }^{1,3}$ Alison G. Power, ${ }^{1}$ Allison A. Snow, ${ }^{2}$ and Lawrence J. Spencer ${ }^{2}$ \\ ${ }^{1}$ Department of Ecology and Evolutionary Biology, Corson Hall, Cornell University, Ithaca, New York 14853 USA \\ ${ }^{2}$ Department of Evolution, Ecology, and Organismal Biology, Ohio State University, Columbus, Ohio 43210 USA
}

\begin{abstract}
The development of crops genetically engineered for pathogen resistance has raised concerns that crop-to-wild gene flow could release wild or weedy relatives from regulation by the pathogens targeted by the transgenes that confer resistance. Investigation of these risks has also raised questions about the impact of gene flow from conventional crops into wild plant populations. Viruses in natural plant populations can play important roles in plant fecundity and competitive interactions. Here, we show that virus-resistance transgenes and conventional crop genes can increase fecundity of wild plants under virus pressure. We asked how gene flow from a cultivated squash (Cucurbita pepo) engineered for virus resistance would affect the fecundity of wild squash (C. pepo) in the presence and absence of virus pressure. A transgenic squash cultivar was crossed and backcrossed with wild C. pepo from Arkansas. Wild C. pepo, transgenic backcross plants, and non-transgenic backcross plants were compared in field plots in Ithaca, New York, USA. The second and third generations of backcrosses (BC2 and BC3) were used in 2002 and 2003, respectively. One-half of the plants were inoculated with zucchini yellow mosaic virus (ZYMV), and one-half of the plants were maintained as healthy controls. Virus pressure dramatically decreased the fecundity of wild $C$. pepo plants and non-transgenic backcross plants relative to transgenic backcross plants, which showed continued functioning of the virus-resistance transgene. In 2002, non-transgenic backcross fecundity was slightly higher than wild C. pepo fecundity under virus pressure, indicating a possible benefit of conventional crop alleles, but they did not differ in 2003 when fecundity was lower in both groups. We detected no fitness costs of the transgene in the absence of the virus. If viruses play a role in the population dynamics of wild C. pepo, we predict that gene flow from transgenic, virus-resistant squash and, to a much lesser extent, conventionally bred squash would increase C. pepo fecundity. Studies such as this one, in combination with documentation of the probability of crop-to-wild gene flow and surveys of virus incidence in wild populations, can provide a solid basis for environmental risk assessments of crops genetically engineered for virus resistance.
\end{abstract}

Key words: conventional crop; crop-wild hybridization; Cucurbita pepo; fitness; gene flow; genetic engineering; introgression; plant virus; risk assessment; transgenic plants; virus resistance; zucchini yellow mosaic virus.

\section{INTRODUCTION}

Pest resistance is a major objective in the development of genetically engineered (GE) crops, and both virusresistant and insect-resistant GE crops are grown commercially in the United States and elsewhere. Documented gene flow and hybridization between at least 48 cultivated plants and their wild or weedy relatives (Ellstrand 2003a, b) prompts concern that GE crop-towild gene flow could increase the fitness of related wild or weedy plants and improve their competitive abilities in both natural and agricultural habitats (Ellstrand and Hoffman 1990, Snow and Palma 1997, Power 2002, Pilson and Prendeville 2004, Andow and Zwahlen 2006). Our

Manuscript received 16 January 2008; revised 13 August 2008; accepted 30 September 2008; final version received 25 October 2008. Corresponding Editor: E. Newell.

33E-mail:kd124@cornell.edu limited knowledge of how viruses affect wild plant populations poses a major challenge in predicting the effects of virus-resistance transgenes in wild plant populations. In this experimental study, we examined the fitness effects of virus infection on wild squash (Cucurbita pepo) and how transgenic virus resistance in wild squash may modify those effects. Studies such as this one can be used in combination with information about crop-to-wild gene flow and virus incidence in wild populations for environmental risk assessments.

The few studies of virus infection in wild plant populations indicate that virus resistance may affect plant fitness. Virus infections can be ubiquitous in wild plant populations (MacClement and Richards 1956, Yahara and Oyama 1993, Raybould et al. 1999, Malmstrom et al. 2005), can cause significant reductions in vegetative and reproductive performance (Friess and Maillet 1996, Funayama et al. 1997, Maskell et al. 1999, Power 2002), and can alter intra- and interspecific 
competitive interactions in plant communities (Catherall 1966, Catherall and Griffiths 1966, Friess and Maillet 1997, Power and Mitchell 2004). Few studies, however, have comprehensively measured fitness impacts of viruses or directly assessed the impact of virus-resistant transgenes on plant fitness (but see Fuchs et al. 2004b).

In this study, we examine the impact of genetically engineered virus resistance on wild plant fitness in the presence and absence of virus inoculum. We also compare the impact of conventionally bred crop genes to that of transgenes. We ask two questions necessary to differentiate the effects of conventional and engineered resistance traits on wild plants (see NRC 2002 for discussion of appropriate questions). First, do transgenic and non-transgenic crop-wild hybrids differ in fitness in the presence and absence of pest pressure? Second, to determine if other crop genes affect resistance, do nontransgenic crop-wild hybrids differ in fitness from the wild plant in the presence and absence of pest pressure? We addressed these questions by comparing fitness components of wild plants and backcross progeny from crop-wild hybrids, one-half of which were transgenic, in common garden experiments.

\section{Study system}

Squash is currently the most convenient study system in the United States with which to investigate the impacts of GE virus resistance in related wild populations, because it is the only GE, virus-resistant crop that is federally deregulated, is commercially available, and has wild relatives in the United States (Accord 1996, Fuchs et al. 2004b). CZW-3 is a yellow crookneck summer squash line (C. pepo ssp. ovifera var. ovifera; Seminis, Oxnard, California, USA) that has been engineered to resist three of the five major viruses that cause significant damage to cucurbit crops worldwide: cucumber mosaic virus (CMV), zucchini yellow mosaic virus (ZYMV), and watermelon mosaic virus-2 (WMV2). Resistance is mediated by a construct containing each virus' coat protein gene inserted into the squash genome (Tricoli et al. 1995). Rigorous risk assessment of crop-to-wild transgene flow from CZW-3 cultivars had not been completed at the time of deregulation (NRC 2002, 2004).

Wild, undomesticated squash (C. pepo ssp. ovifera vars. ozarkana and texana) ranges from Texas to Alabama and north through the Ozark Mountains and the Mississippi River Valley (Cowan and Smith 1993). Wild $C$. pepo can be an agricultural weed (Oliver et al. 1983). ZYMV, WMV-2, and CMV infect wild squash (APHIS/USDA 1994, Quemada et al. 2002, Laughlin 2006); however, the epidemiology of these viruses in wild $C$. pepo is not well understood.

Cultivated $C$. pepo and wild $C$. pepo interbreed to produce fertile progeny, and alleles from conventionally bred $C$. реро have been detected in wild $C$. реро populations (Kirkpatrick and Wilson 1988, DeckerWalters et al. 1993, 2002). Spencer and Snow (2001) showed that F1 hybrids from crosses between wild $C$. pepo (var. ozarkana) and ZW-20 (a transgenic virusresistant squash similar to $\mathrm{CZW}-3$ ) experienced reduced reproductive output under ambient conditions, but not so low to prevent further crop gene passage to ensuing generations (Spencer and Snow 2001). Fecundity increased in the following two backcross generations (Spencer 2001). Fuchs et al. (2004a) showed that gene movement from cultivated $C$. pepo into wild populations is less likely when wild $C$. pepo populations are under high virus pressure; however, given the absence of the three viruses in wild $C$. pepo in some years (APHIS/ USDA 1994, Quemada et al. 2002, Laughlin 2006), high virus pressure would not be common enough to fully prevent transgene movement into wild $C$. pepo in the long term.

Fuchs et al. (2004b) demonstrated that when multiple virus species spread via naturally occurring aphid vectors across a population of $\mathrm{CZW}-3$, wild C. pepo, and the $\mathrm{F} 1, \mathrm{BC} 1$ and $\mathrm{BC} 2$ generations, transgenic backcrosses had higher reproductive output than wild C. pepo. The fecundity effects of each pathogen, however, were inherently confounded by variation in the other infecting virus species, time of virus transmission, and vector species. By controlling for virus species, time of transmission, and transmission mechanism, our study complements Fuchs et al. (2004b) by dissecting the underlying dynamics of the fecundity patterns demonstrated in their study.

Here, we examine the effects of the virus-resistance transgene when a single target virus, ZYMV (Connecticut strain), infects wild C. pepo. Using the $\mathrm{BC} 2$ and $\mathrm{BC} 3$ generations of GE crop-wild crosses, we asked, after two generations of backcrossing to wild plants: (1) How does the presence of a virus-resistance transgene affect the fecundity of backcross plants under virus pressure? (2) How does the presence of conventional crop genes affect the fecundity of backcross plants under virus pressure? (3) What is the cost of a virus-resistance transgene and of conventional crop genes in backcross plants in the absence of virus infection? (4) Does the backcross phenotype impede further introgression into the wild $C$. pepo population?

\section{Methods \\ Experimental approach}

Investigating potential risks of crop-to-wild transgene flow requires a study organism and an experimental design that shed light on the effects of transgene introgression, but avoid the risks under investigation. By studying a GE virus-resistant Cucurbita pepo that has been federally deregulated, we were able to plant the transgenic organism in openly pollinated fields. We prevented transgene escape into wild $C$. pepo populations by conducting our study in New York outside the range of wild $C$. pepo. The New York study plants produced fruit and seed yields comparable to similar 
field experiments conducted within the native range of C. pepo (see Spencer and Snow 2001).

To mimic introgression of $\mathrm{GE}$ virus resistance into wild $C$. pepo, we backcrossed transgenic crop-wild hybrids with wild $C$. pepo (var. ozarkana). We compared the fecundity of transgenic $\mathrm{BC} 2$ and $\mathrm{BC} 3$ generations with wild $C$. pepo to determine if the virus-resistance transgene could protect wild plants and enhance their fecundity. We assumed that the only difference between transgenic and non-transgenic backcross plants was the presence of the transgene and other genes tightly linked to this locus. We used comparisons among nontransgenic $\mathrm{BC} 2$ and $\mathrm{BC} 3$ generations and wild C. pepo to distinguish fecundity effects due to conventional crop-gene introgression from those due to transgene introgression.

The study focused on ZYMV infection. ZYMV is an important virus in cultivated cucurbit systems and caused yield losses in Arkansas (origin of the wild $C$. pepo in this study) and worldwide during the 1980s and 1990s (Mcleod et al. 1986, Hander et al. 1993, Desbiez and Lecoq 1997). Hereafter, we refer to the ZYMV coat protein transgene that mediates ZYMV-resistance as the "transgene."

\section{Crosses}

We obtained an F1 generation through a series of greenhouse crosses between seeds from $\sim 15$ transgenic CZW-3 squash and seven wild $C$. pepo collected from the White and Buffalo River watersheds in Arkansas (as described in Spencer 2001). Genotypes were distributed evenly throughout all treatments in the study. The transgene in CZW-3 is hemizygous and segregates at a 1:1 ratio (Tricoli et al. 1995). In each successive BC generation we identified transgenic $\mathrm{F} 1$ or BC progeny by enzyme-linked immuno-sorbent assay (ELISA) to detect the transgene neomycin phosphotransferase II marker. We used these transgenic plants as pollen donors on wild maternal plants derived from populations in the White and Buffalo River watersheds.

\section{Field experiments}

Wild and BC (BC2 in 2002; BC3 in 2003) individuals were transplanted from the greenhouse to the field at the 3-4 true leaf stage. Plants were transplanted on 8 July in 2002. In 2003 early summer floods delayed the growing season, so young seedlings were transplanted on 29 July. We treated seedlings with a prophylactic application of a bifenthrin insecticide to prevent virus transmission and contamination in the greenhouse. Two days prior to transplanting, one-half of the wild (W), transgenic (TBC), and non-transgenic (NTBC) seedlings were mechanically inoculated with ZYMV (Connecticut strain).

Field design.-We used a split-plot design where infection status (virus-inoculated or healthy control) was applied at the whole plot level, and plant type (W, TBC, or NTBC) was applied at the split-plot level. Each year, a set of $\mathrm{W}, \mathrm{TBC}$, and NTBC individuals $(20 \mathrm{~W}, 20$ NTBC, 10 TBC in 2002; $10 \mathrm{~W}, 10$ NTBC, 10 TBC in 2003) was randomly assigned positions in each of four half-acre (0.2-ha) plots. Two plots received plants inoculated with ZYMV, and two control plots received uninoculated control plants. Plants were separated by $4 \mathrm{~m}$ in 2002 and $5 \mathrm{~m}$ in 2003 to minimize competition. Plots were located as far as possible from other cucurbit plantings to avoid virus and other cucurbit pathogen contamination and, with one exception, at least $1.2 \mathrm{~km}$ from each other to minimize aphid transmission of ZYMV to the control plots. In 2003, a virus-inoculated plot was located $0.75 \mathrm{~km}$ downwind of a control plot. In 2002 one virus-inoculated plot was severely damaged by deer herbivory and was removed from the final analysis.

Field maintenance.-Plots were weeded regularly and irrigated when necessary. We applied pesticides to the extent necessary to prevent pests and pathogens from interfering with detection of fecundity effects of virus infection. All plots received identical insecticide treatments. We removed individuals that contracted nonZYMV virus infections in the field (four plants in 2002 and one plant in 2003). Final sample sizes for each test are shown in the figures.

Fitness measurements.-We measured six components of fitness: female flower number, male flower number, fruit number, seed number per plant, pollen production, and biomass. We counted and marked female and male flowers produced on each plant every 3-4 days. Flowers were open-pollinated in the plots. We tagged fruits within two to three days after pollination and classified fruit age by week of pollination. Before first frost, we harvested the plants and counted fruits from each plant (20-26 September in 2002; 2-3 October in 2003), nine to 11 days after final flower counts. Fruits produced from flowers that developed after the final flower count were classed in a final fruit age class distinct from all previously marked fruit.

We estimated total seed production per plant using fruit numbers and size. During the final two weeks before harvest, fruits were too immature for accurate seed count and were excluded from seed number estimates. In 2002, we estimated seed numbers using a predictive model based on the volume of each fruit. Seed counts from a subsample indicated that this model was a good predictor of seeds per fruit in $\mathrm{BC}$ and wild $C$. pepo fruits $\left(n=106, r^{2}=0.857, P<0.0001\right)$ and was robust across multiple fruit age classes. Seed number did not vary greatly among fruits from an individual plant. We combined the predictive model with a conservative subsampling strategy. We measured 10 randomly selected fruits from each plant pollinated in each of the first three pollination weeks and estimated seed number. Mean seed number per fruit for each pollination week for each plant was multiplied by the respective number of fruits in the pollination week to attain seeds per pollination week. We summed seed production from the three weeks to give total seed number for an 
TABLE 1. Plant type-level effects on fitness measurements in control and virus-infected (zucchini yellow mosaic virus) plots of wild squash (Cucurbita pepo) and on transgenic and non-transgenic crop-wild C. pepo hybrids (second backcross generation) for 2002 (ANOVA).

\begin{tabular}{|c|c|c|c|c|c|c|c|c|c|}
\hline \multirow[b]{2}{*}{ Source } & \multicolumn{3}{|c|}{$\begin{array}{l}\text { Number of } \\
\text { female flowers }\end{array}$} & \multicolumn{3}{|c|}{$\begin{array}{l}\text { Number } \\
\text { of fruit }\end{array}$} & \multicolumn{3}{|c|}{$\begin{array}{l}\text { Number } \\
\text { of seeds }\end{array}$} \\
\hline & $\mathrm{df} \dagger$ & $F$ & $\chi^{2}$ & $\mathrm{df}^{\dagger}$ & $F$ & $\chi^{2}$ & $d f^{\dagger} \dagger$ & $F$ & $\chi^{2}$ \\
\hline \multicolumn{10}{|l|}{ Control } \\
\hline Plant type & 2,92 & 2.66 & & 2,91 & $6.56^{* *}$ & & 2,91 & 0.23 & \\
\hline Plot & 1 & & 0.0 & 1 & & 0.0 & 1 & & 0.3 \\
\hline Plot $\times$ plant type & 1 & & $41.3 * * *$ & 1 & & $6.0^{* *}$ & 1 & & $6.0 * * *$ \\
\hline \multicolumn{10}{|l|}{ Virus-infected } \\
\hline Plant type & 2,44 & $28.97 * * *$ & & 2,44 & $21.26^{* * *}$ & & 2,44 & $47.73^{* * *}$ & \\
\hline
\end{tabular}

Note: See Fig. 1 for sample sizes.

$\dagger$ Numerator, denominator df for fixed effects ( $F$ tests); chi square distribution df for random effects.

$* * P<0.01 ; * * * P<0.001$.

individual plant. The 2002 data showed that the mean seed number of a random sample of fruits from an individual plant could be used to predict plant seed production. In 2003, we counted seeds from three randomly selected fruits from each of five fruit age classes on each plant. Mean seed number for each age class within a plant was multiplied by the number of fruits in the respective age class on the plant to give total seed number for the plant.

In 2002 we measured aboveground biomass by weighing the entire plant in the field and then drying one vine per plant in a drying oven. The dry-to-wet mass ratio of each plant's respective vine was used to estimate the plant's total vegetative dry mass. In 2003, plants were small enough to dry the entire aboveground vegetative mass in ovens. In both years, fruits and seeds from each plant were dried and weighed for reproductive biomass.

We compared pollen production among treatments in 2003 by estimating total pollen mass. We limited pollen collection to two days in mid-September to minimize differences in pollen production due to changing weather conditions and still allow time for male flower production. An anther from each plant was placed in a micro-centrifuge tube to complete anthesis overnight at room temperature. We then added $750 \mu \mathrm{L}$ distilled water to the micro-centrifuge tube and vibrated the tube on a VWR Vortex Genie (VWR, West Chester, Pennsylva- nia, USA) at the high setting for $30 \mathrm{~s}$ to remove the pollen from the anther and immediately removed the anther from the tube. Then $500 \mu \mathrm{L}$ of each suspension was dried in a drying oven at $60^{\circ} \mathrm{C}$ and weighed with an ultra-microbalance.

Due to the loss of one virus-infected plot, we were unable to compare the effect of plant type between virusinfected and control plots in 2002. We instead separately examined the effect of plant type on the six fitness components within the remaining virus plot using a general linear model ANOVA and within the control plots using a mixed-model ANOVA, where plot was included as a random effect (GLM procedure, SAS 2003; MIXED procedure, SAS 2003). For 2003, the effect of plant type and infection status on the six fitness components was examined using a mixed-model ANOVA (MIXED procedure, SAS 2003). Plot nested within infection status was considered the whole-plot error and included as a random effect in all six analyses. We tested the effect of the transgene and conventional crop genes on each response variable within and across infection status using Tukey-Kramer mean comparisons.

In addition to analysis of the full data set, we analyzed a data set standardized for an 80-day growing season duration. End-of-season biomass could not be standardized in this manner and was excluded from the standardized data set. Despite truncating the 2002 data

TABLE 2. Virus infection level and plant type-level effects on fitness measurements on wild squash (Cucurbita pepo) and on transgenic and non-transgenic crop-wild C. pepo hybrids (third backcross generation) for 2003 (ANOVA).

\begin{tabular}{|c|c|c|c|c|c|c|c|c|c|c|c|c|}
\hline \multirow[b]{2}{*}{ Source } & \multicolumn{3}{|c|}{ Female flower no. } & \multicolumn{3}{|c|}{ Fruit no. } & \multicolumn{3}{|c|}{ Seed no. } & \multicolumn{3}{|c|}{ Male flower no. } \\
\hline & $\mathrm{df} \uparrow$ & $F$ & $\overline{\chi^{2}}$ & $\mathrm{df} \dagger$ & $F$ & $\chi^{2}$ & $d f \dagger$ & $F$ & $\chi^{2}$ & $\mathrm{df} \dagger$ & $F$ & $\overline{\chi^{2}}$ \\
\hline Infection & $1,1.95$ & $107.35^{* *}$ & & $1,1.94$ & $22.44^{*}$ & & $1,1.98$ & $19.22 *$ & & 1,2 & 5.75 & \\
\hline Plant type & 2,103 & $35.49 * * *$ & & 2,102 & $44.99 * * *$ & & 2,102 & $45.62 * * *$ & & 2,102 & $11.21 * * *$ & \\
\hline Infection $\times$ plant type & 2,103 & $33.8 * * *$ & & 2,102 & $39.6^{* * *}$ & & 2,102 & $30.35 * * *$ & & 2,102 & $13.31 * * *$ & \\
\hline Plot(infection) $\ddagger$ & 1 & & 0 & 1 & & $4.4^{*}$ & 1 & & $6.8^{* *}$ & 1 & & 7.8 \\
\hline
\end{tabular}

Note: See Figs. 1 and 2 for sample sizes

$* P<0.05$; ** $P<0.01$; *** $P<0.001$.

$\uparrow$ Numerator, denominator df for fixed effects ( $F$ tests); chi square distribution df for random effects.

$\$$ Plot nested in infection is the whole plot error; whole plot is a random effect. 
TAble 1. Extended.

\begin{tabular}{|c|c|c|c|c|c|}
\hline \multicolumn{3}{|c|}{$\begin{array}{l}\text { Number of } \\
\text { male flowers }\end{array}$} & \multicolumn{3}{|c|}{ Biomass } \\
\hline $\mathrm{df}^{\dagger}$ & $F$ & $\chi^{2}$ & $\mathrm{df}^{\prime} \dagger$ & $F$ or & $\chi^{2}$ \\
\hline $\begin{array}{c}2,90 \\
1 \\
1\end{array}$ & 0.26 & $\begin{array}{l}0.0 \\
44.9^{* * *}\end{array}$ & $\begin{array}{c}2,90 \\
1 \\
1\end{array}$ & 1.21 & $\begin{array}{l}0.0 \\
24.0^{* * *}\end{array}$ \\
\hline 2,44 & $34.43 * * *$ & & 2,44 & $23.39 * * *$ & \\
\hline
\end{tabular}

at 80 days, the standardized data showed no difference from the full data set in statistical patterns, so full season data from 2002 and 2003 were used for the final analyses.

Morphology and flowering phenology.-We compared morphology and flowering phenology to assess whether BC2 plants retained crop characters maladapted to wild C. pepo habitat and whether flowering phenology might inhibit transgene introgression. In 2002 control plots, we measured the length of the 10th internode on the oldest shoot of each plant. Long internode lengths indicate a vine-like morphology. We measured the area of leaves from the tenth node along the oldest shoot with an LI3100 area meter (LI-COR Biosciences, Lincoln, Nebraska, USA). Plants with significant damage to the leaf at node-10 were not included. To compare flowering period overlap, we calculated the number of days from germination to first male and female flower for each plant. We examined the effect of plant type on internode length, leaf area, and first flower day using a mixedmodel ANOVA (MIXED procedure, SAS 2003), where plot and interactions with plot were included as random effects. We examined Tukey-Kramer mean comparisons to test plant type effects.

\section{RESULTS}

Virus symptoms

Virus plots and control plots showed different patterns of ZYMV symptom expression across plant types. Plants in control plots showed no ZYMV

TABle 2. Extended.

\begin{tabular}{|c|c|c|c|c|c|}
\hline \multicolumn{3}{|c|}{ Pollen production } & \multicolumn{3}{|c|}{ Biomass } \\
\hline$d f \dagger$ & $F$ or $\chi^{2}$ & $\overline{\chi^{2}}$ & $\mathrm{df}^{\dagger} \dagger$ & $F$ or $\chi^{2}$ & $\chi^{2}$ \\
\hline $1,2.26$ & 7.06 & & $1,1.85$ & $81.24 * * *$ & \\
\hline $2,79.7$ & $5.37 * *$ & & 2,103 & $30.68 * * *$ & \\
\hline $2,79.7$ & 2 & & 2,103 & $22.28 * * *$ & \\
\hline 1 & & 0.2 & 1 & & 0.2 \\
\hline
\end{tabular}

symptoms. In virus plots, all wild plants and $60 \%$ of non-transgenic BC plants showed severe ZYMV symptoms throughout the growing season. Approximately $40 \%$ of non-transgenic BC plants exhibited mild virus symptoms. During the last 2-3 weeks of the 2002 experiment, transgenic $\mathrm{BC} 2$ plants in virus plots developed mild chlorotic dotting similar to the extremely mild, late-season virus symptoms reported in the original CZW-3 cultivar field trials (Tricoli et al. 1995, Fuchs et al. 1998). Late-season chlorotic dotting did not affect reproduction (Tricoli et al. 1995, Fuchs et al. 1998). By September of both years, all plots experienced some bacterial wilt disease. Individuals within plots appeared to be affected uniformly by bacterial wild disease, and the infection did not influence treatment effects.

\section{Fitness components}

The five fitness components measured both years (male flower number, female flower number, fruit number, seed number, and total biomass) showed similar yet distinct patterns each year. The patterns in the virus-infected and control plots in 2002 suggest that the effect of ZYMV infection differed among plant types and the significant infection status-by-plant type interaction in 2003 confirms this (Tables 1 and 2). In virus plots, ZYMV dramatically reduced seed number in nontransgenic $\mathrm{BC} 2, \mathrm{BC} 3$, and wild $C$. pepo plants, but ZYMV pressure did not reduce seed number of transgenic $\mathrm{BC} 2$ and $\mathrm{BC} 3$ plants (Fig. 1). Although a statistical comparison was not feasible, transgenic $\mathrm{BC} 2$ fitness in 2002 virus-infected plots appears to be higher than in 2002 control plots (Fig. 1). This is likely due to differences in plot growing conditions rather than a positive effect of virus pressure. Transgenic and nontransgenic $\mathrm{BC} 2$ and $\mathrm{BC} 3$ plants in control plots did not differ from wild C. pepo in fecundity or biomass measurements with the exception of fruit production (Fig. 1). In 2002 control plots, non-transgenic BC2 fruit production was $40 \%$ lower than wild fruit production. In 2003 control plots, fruit production in non-transgenic BC3 plants did not differ from wild fruit production (Fig. 1).

In the 2003 virus-infected plots, wild plants produced $\sim 9 \%$ of the female flowers, $6 \%$ of the fruit, but only $3 \%$ of the seeds produced by transgenic $\mathrm{BC} 3$ plants (Fig. 1). Wild plants in 2002 showed similar patterns under virus pressure, but failed to produce seeds. It should be noted that female flower number represents a conservative test of female reproductive fitness under virus pressure, because female flowers on plants with high expression of ZYMV symptoms did not fully open and had deformed stigmas. Therefore, female flower counts on highly symptomatic plants overestimated the number of flowers that pollinators could effectively pollinate.

Patterns in pollen production appear to be consistent with other fitness components (Fig. 2, Table 2), but the resolution of our pollen quantification method may have 


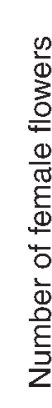
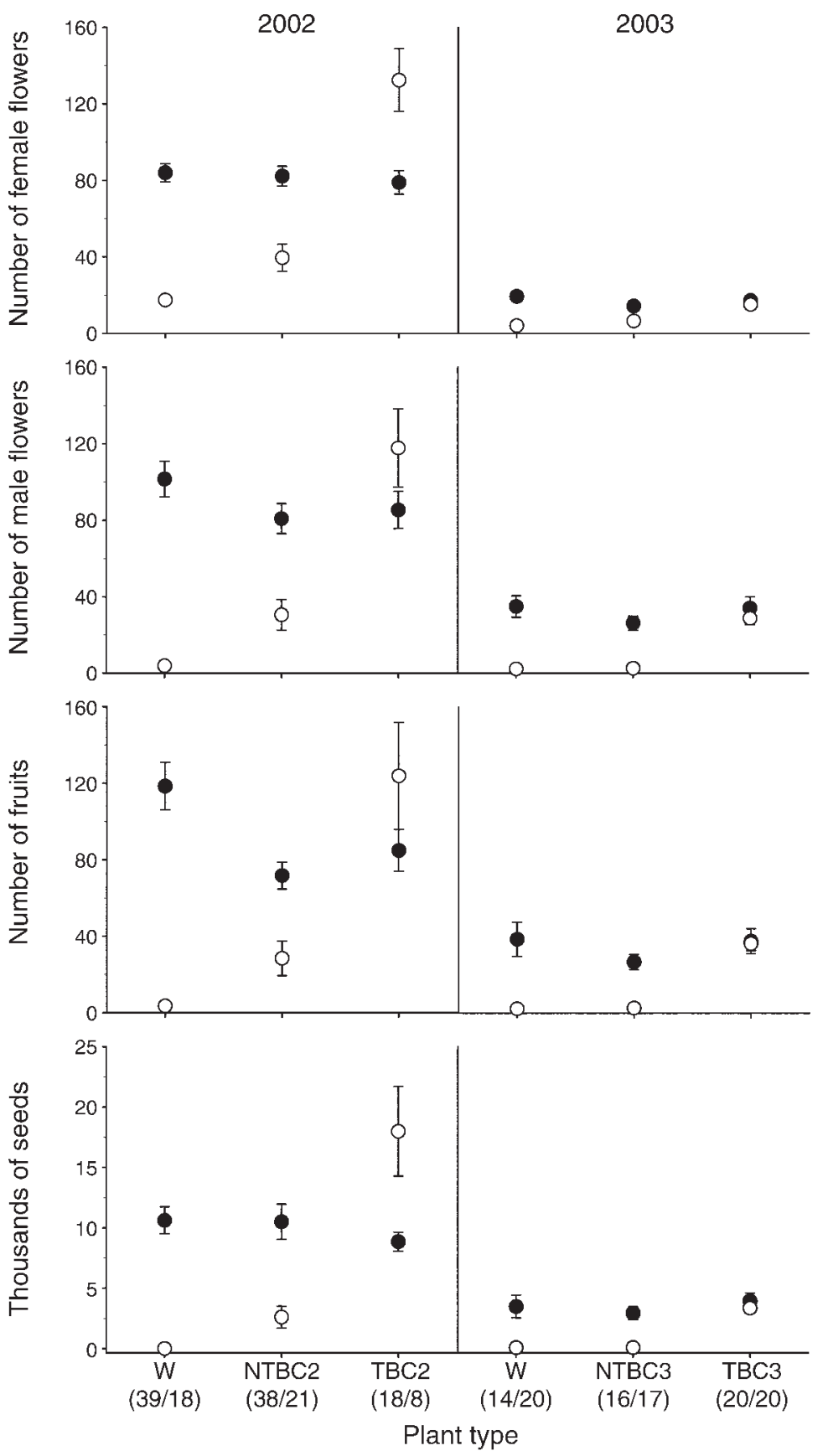

FIG. 1. Reproductive output (except pollen production) (mean $\pm \mathrm{SE}$ ) in control (solid circle) and virus-infected (open circle) plots in 2002 and 2003; W, wild C. pepo; NTBC, non-transgenic backcross; TBC, transgenic backcross. Sample sizes for control plots and virus-infected plots, respectively, are shown in parentheses below each plant type for each year on the bottom $x$-axis. All fitness components (biomass not shown in figure) follow the same within-year patterns with one exception. In 2002, control plot W, NTBC2, and TBC2 do not differ from each other with the exception that W and NTBC2 fruit significantly differ $(\alpha=0.05)$. In 2002 virus-infected plots, W, NTBC2, and TBC2 all significantly differ from each other $(\alpha=0.05)$. In 2003, control plot W, NTBC3, and TBC3 do not differ from each other or from TBC3 in the virus-infected plot $(\alpha=0.05)$. In 2003 virus-infected plots, TBC3 significantly differs from W and NTBC3, but W and NTBC3 do not differ $(\alpha=0.05)$. Note that, in some cases, fruit production is higher than female flower production in the same treatment, because fruits were harvested 9-11 days after the final flower count.

been too coarse to differentiate statistically among some treatments. The infection-by-plant type interaction was not significant (Table 2), but wild pollen production was marginally lower than transgenic $\mathrm{BC} 3$ pollen production under virus pressure (Fig. 2). Both wild and nontransgenic BC3 plants infected with ZYMV produced shrunken and misshapen anthers that often did not fully release pollen at anthesis. Virus-infected male flowers 


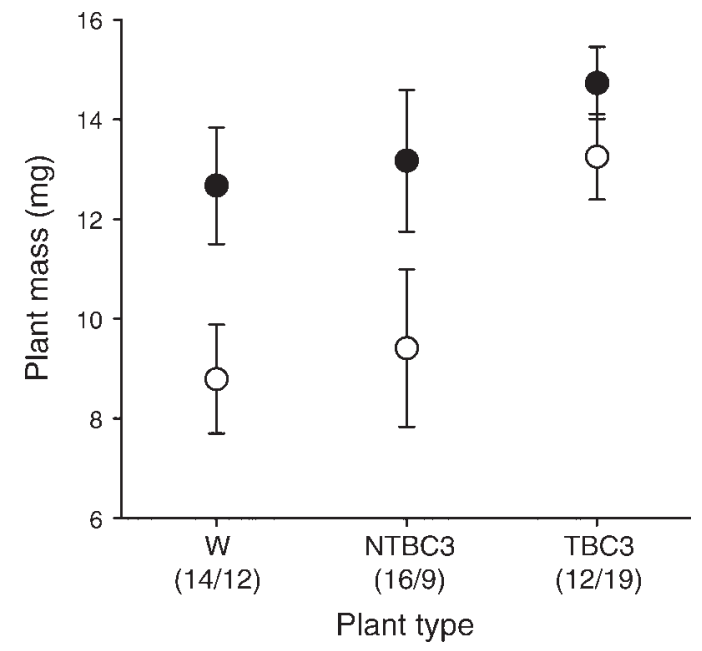

FIG. 2. Pollen production (mean $\pm \mathrm{SE}$ ) in control (solid circles) and virus-infected (open circles) plots in 2003. Key to abbreviations: W, wild $C$. pepo; NTBC, non-transgenic backcross; TBC, transgenic backcross. Sample sizes for control plots and virus-infected plots, respectively, are shown in parentheses below each plant type for each year on the $x$ axis. Pollen masses of $\mathrm{W}, \mathrm{NTBC}$, and TBC in control plots do not differ significantly from each other or from their respective plant types in virus-infected plots $(\alpha=0.05)$. In virus-infected plots, the difference between $\mathrm{W}$ and $\mathrm{TBC}$ is marginally significant $(P=0.0561)$. NTBC does not differ significantly from $\mathrm{W}$ or TBC in virus-infected plots $(\alpha=0.05)$.

typically did not fully open and thereby prevented pollinators from accessing pollen. Therefore, our male flower counts and pollen production measurements were conservative tests of male reproductive fitness for infected wild $C$. pepo plants and non-transgenic BC3 plants.

In 2002, non-transgenic BC2 plants performed slightly but consistently better than wild $C$. pepo across all measures of reproductive and vegetative output (except pollen production) under virus infection (Fig. 1). This suggests that the crop had some degree of conventional resistance to the virus. Under virus pressure, nontransgenic BC2 plants produced, on average, 2600 seeds; whereas, on average, wild $C$. pepo did not produce seeds (Fig. 1). Non-transgenic BC3 plants and wild plants did not exhibit differences in reproductive or vegetative output under virus pressure in 2003 (Figs. 1 and 2).

\section{Morphology and flowering phenology}

In control plots wild plants showed some small yet significant differences from BC2 plants in morphology, but the differences were far less dramatic than the differences between wild plants and earlier hybrid generations (Spencer and Snow 2001). The majority of BC2 plants displayed a vine-like morphology visually indiscernible from the wild phenotype, and few BC2 plants expressed a bushy phenotype characteristic of the crop cultivar. Non-transgenic BC2 internodes were marginally shorter than wild internodes $\left(t_{93}=2.31, P\right.$ $=0.0589$; Fig. 3A), and transgenic BC2 internodes were not significantly different than wild $C$. pepo internodes $\left(t_{93}=0.75, P=0.7360\right)$. Transgenic and non-transgenic BC2 leaves were 1.5 and 1.6 times the size of wild $C$. pepo leaves, respectively $\left(t_{84}=3.33, P=0.0007 ; t_{84}=\right.$ $3.85, P=0.0036$, respectively; Fig. 3B). Internode length and leaf area did not differ between transgenic and nontransgenic BC2 plants $\left(t_{93}=1.13, P=0.4968 ; t_{84}=0.07\right.$, $P=0.9972$, respectively). The timing of male flowering commencement did not differ among control plot plant types in $2002\left(F_{2,97}=0.12, P=0.8826\right)$; however, nontransgenic $\mathrm{BC} 2$ plants began female flower production four days before wild plants $\left(t_{96}=3.34, P=0.0034\right)$. The timing of first female flower in transgenic BC2 plants lay between non-transgenic BC2 plants and wild plant and did not significantly differ from either $\left(t_{96}=1.67, P=\right.$ $\left.0.2238 ; t_{96}=1.02, P=0.5677\right)$. The first day of female and male flowering in $\mathrm{BC} 3$ plants in control plots did

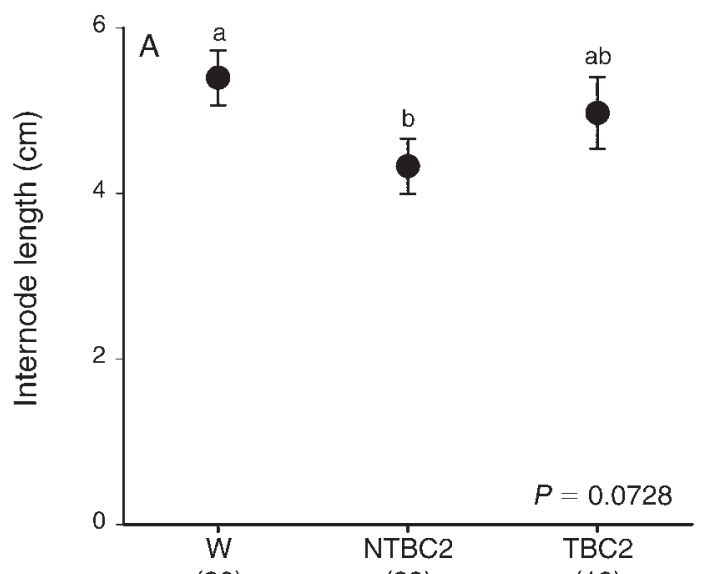

(39)

(38)

(19)

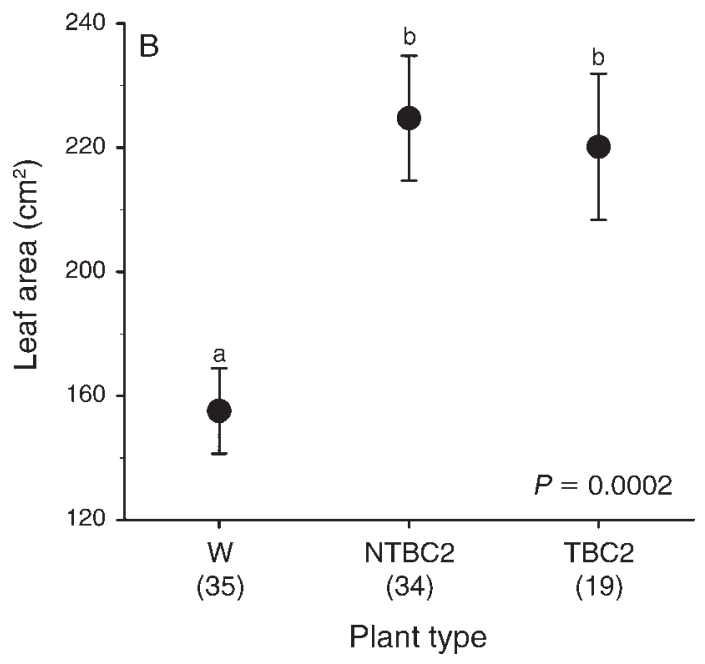

FIG. 3. Vegetative traits (mean $\pm \mathrm{SE}$ ) in control plots in 2002. Key to abbreviations: W, wild C. pepo; NTBC, nontransgenic backcross; TBC, transgenic backcross. Different letters indicate significant differences $(\alpha=0.05)$ between plant types using Tukey-Kramer comparison tests. $P$ values for overall significant effects are shown in the lower right-hand corner of each panel. Sample sizes are shown in parentheses below each plant type on the $x$-axis. 
not differ significantly from wild plants $\left(F_{2,50}=1.40, P=\right.$ $\left.0.2570 ; F_{2,49}=0.11, P=0.8947\right)$.

\section{DisCuSSION}

This study demonstrates that the virus-resistance transgene continues to function in the second and third backcross generations of crop-wild hybrids. By controlling for inoculation timing and excluding CMV and WMV-2 from the experiments, we could attribute all virus infection effects to ZYMV. The transgenic virus resistance and, more subtly, conventional crop genes improve wild squash fecundity under ZYMV pressure. The BC2 generation demonstrated in its fruit production slight remnants of reproductive fitness costs in the cropwild hybrids in the absence of ZYMV pressure, but these costs are absent by the third generation of backcrossing. The results suggest that some morphological crop traits such as shorter internodes could be slightly detrimental to backcross generations in natural habitats, but not to the extent that further introgression would be strongly impeded.

\section{Effect of transgenes on C. pepo fecundity}

Our results suggest that the presence of transgenic virus resistance in wild $C$. pepo would prevent the dramatic drop in fecundity that is typically associated with ZYMV infection. We expect the multi-transgene construct would confer similar protection to wild $C$. pepo under CMV and WMV-2 pressure, as indicated by Fuchs et al. (2004b), though studies of the individual effects of CMV and WMV-2 are necessary to confirm this expectation. With the exception of pollen production in non-transgenic BC plants, ZYMV exerted negative effects on all reproductive stages of wild and non-transgenic BC plants, decreasing seed production by $80-100 \%$. Finer measurement of pollen production with a particle counter (see Quesada et al. 1995) may yet detect decreased pollen counts in virus-infected nontransgenic backcrosses. Quesada et al. (1995) found that mechanical leaf damage to $C$. pepo reduced not only pollen production but also reduced pollen performance. While we did not measure pollen viability or pollen germination, it is possible that virus damage to plants may reduce pollen performance in plants not protected against the virus.

In contrast, BC plants with the virus-resistance transgene did not differ in fecundity from plants in control plots. We cannot rule out the possibility that $\mathrm{BC}$ plants could experience lower fecundity than wild plants under the more competitive and harsh conditions of natural habitats, but it is unlikely these conditions would fully counter the increased fecundity of transgenic $\mathrm{BC}$ plants under virus pressure.

Conventional breeders have undoubtedly selected for more virus-tolerant or resistant individuals over the years. Therefore, it is striking but not altogether surprising that non-transgenic BC2 plants had slightly but consistently higher reproductive output and biomass than wild $C$. pepo under virus pressure. Furthermore, some non-transgenic, $\mathrm{BC} 2$ and $\mathrm{BC} 3$ individuals showed fewer ZYMV symptoms and had larger biomass compared to wild $C$. pepo and other non-transgenic backcross individuals. This indicates that even crop-towild gene flow from a conventional crop not specifically bred for virus resistance could confer some fitness advantage upon wild $C$. pepo under virus pressure.

It is then, at first, puzzling that the non-transgenic BC3 generation did not show higher reproductive output than wild $C$. pepo under virus pressure. Three factors may have contributed to differing patterns between the two backcross generations. First, the 2003 growing season (BC3) was a few weeks shorter than the 2002 season (BC2) due to early summer flooding. To determine if the difference between non-transgenic backcross and wild $C$. pepo emerged at the end of the 2002 growing season, we standardized the 2002 season length to the length of the 2003 season. The two years still showed different patterns for non-transgenic backcross fecundity. Second, variation in environmental conditions could have contributed to the differences. The 2003 growing season was much wetter and cooler than 2002 and may have lowered reproductive and vegetative output. Third, in our crosses we selected only for the presence of the virus-resistance transgene rather than for phenotypically expressed virus resistance or tolerance. This selection approach may have led us to underestimate the effects of conventional crop gene introgression, particularly if the conventional resistance was polygenic. Conventionally bred virus resistance may have been sufficiently diluted across the third backcross generation population that it no longer showed a strong pattern of increased fecundity due to conventional resistance. In support of the third explanation, there remained a few non-transgenic backcross individuals in the BC3 generation that exhibited partial resistance to ZYMV infection.

If viruses exerted pressure on wild squash populations, conventional resistance would undergo positive selection in the same manner as predicted for transgenic virus resistance. If conventionally bred resistance were controlled by a gene at a single locus or a few tightly linked genes, as is engineered resistance, conventional resistance might drift neutrally in the wild population under healthy conditions. If gene expression of conventional resistance were recessive or polygenic, as in several conventionally bred crops resistant to potyviruses (Khetarpal et al. 1998, Diaz-Pendon et al. 2004), then the resistance phenotype may become more diluted in a wild population over several generations of hybridization in healthy conditions.

\section{Effect of morphological and phenological crop traits}

Under healthy conditions, there were slight morphological and phenological differences between BC2 plants and wild $C$. pepo. Transgenic and non-transgenic individuals did not differ in these morphological 
measurements, indicating that the differences are caused by conventional crop genes rather than the transgene. Longer internodes give $C$. pepo a viney architecture that allows the plant to effectively reach sunlight when growing on forest edges. Most F1 hybrids had short internodes $(2-4 \mathrm{~cm})$ and displayed a shrub-like architecture typical of cultivated varieties (Spencer and Snow 2001, Fuchs et al. 2004b). Fuchs et al. (2004b) also show that $\mathrm{BC} 1$ and $\mathrm{BC} 2$ generations are similar in shoot length to wild $C$. pepo. In this study both transgenic and non-transgenic BC2 plants displayed a viney architecture that was visually indistinguishable from wild $C$. реро. The $1-\mathrm{cm}$ difference in internode length between non-transgenic $\mathrm{BC}_{2}$ plants and wild plants would not likely prevent non-transgenic $\mathrm{BC}_{2}$ plants from surviving and successfully reproducing in wild $C$. реро habitat. Remaining differences in internode length may well disappear within one to two more generations of backcrosses. Spencer (2001) reported that F1 and BC1 hybrid leaves were $\sim 50 \%$ greater in area than wild $C$. pepo leaves. Here we show that the $\mathrm{BC} 2$ generation plants have similarly larger leaves. It has long been recognized that smaller leaves maintain better water use efficiency (Monteith 1973), so hybrid plants may be less water-use efficient. Whereas F1 hybrid and wild $C$. pepo flowering periods were slightly offset yet highly overlapping (Spencer and Snow 2001), the flowering phenology of wild and backcross plants nears convergence by the $\mathrm{BC} 2$ generation and converges completely in the $\mathrm{BC} 3$ generation. Most F1 hybrids lack the viney architecture that allows wild $C$. pepo to escape being shaded out by neighboring plants (Spencer and Snow 2001). The bushy morphology of F1 hybrids may hinder survival in the wild habitat of $C$. pepo; however, by the third generation of introgression, vegetative architecture and flowering phenology are not substantial barriers against further introgression. From these data and past evidence of crop-to-wild introgression events in wild $C$. pepo populations (Decker-Walters et al. 1993), we conclude that the virus-resistance transgene could successfully enter a wild $C$. pepo population in the absence of virus pressure.

\section{Risk assessment of transgenic and conventional virus resistance in squash}

This study demonstrates that transgenic virus resistance could have significant impacts on wild $C$. pepo populations, depending on the prevalence of virus infection in wild $C$. pepo. In addition, we found that conventionally bred resistance or tolerance also has the potential to impact wild $C$. pepo populations when exposed to viral infection. These results build upon and extend those reported in previous studies (Spencer 2001, Spencer and Snow 2001, Fuchs et al. 2004a, b).

The incidence patterns of ZYMV, CMV, or WMV-2 in wild $C$. реро populations are not well understood, rendering it difficult to fully predict the consequences of introgression of a virus-resistance transgene into wild $C$. pepo. Cucurbit viruses are unpredictable yet highly damaging pathogens in agriculture (Lecoq et al. 2003), and their prevalence is sporadic in wild $C$. pepo. Several surveys conducted over the past decade have shown low incidence of ZYMV, CMV, and WMV-2 in wild C. pepo populations (APHIS/USDA 1994, Quemada et al. 2002, Laughlin 2006). At least one individual was infected by one or more viruses in $38 \%$ of the 53 populations surveyed in these studies. These surveys provide conservative estimates of virus incidence, because (1) $C$. pepo plants stunted by virus infection may escape detection during surveys due to difficulties in locating small individuals in the field; (2) infected plants in a more competitive, wild habitat may not have the high survival rate seen in our study and therefore may die before detection; and (3) year-to-year virus infection patterns are known to be highly variable in agricultural and natural populations (Thresh 1974). Short-term studies may not adequately describe the long-term virus presence in wild populations.

Wild plants and their pathogens are expected to regulate each other to low population levels (Antonovics 1999), but even a very low pathogen incidence can have severe ramifications on the population dynamics of a plant population (Antonovics et al. 1997). Therefore, introgression of virus resistance, transgenic or conventional, could impact the population dynamics of wild $C$. реро, despite the low virus incidence detected in natural populations. To better predict the effect of virus resistance on wild $C$. pepo population dynamics and community interactions, we need data on the long-term patterns of virus incidence and their role in regulating wild $C$. pepo populations.

If ZYMV infects and regulates a wild C. pepo population, then the entry of transgenic virus resistance would increase the fecundity of those plants carrying the transgene. Transgenic resistance would be under positive selection and likely increase in frequency in the $C$. pepo population. Eventually, the population may be released from regulation by the virus. Presence of conventional crop genes expressing virus tolerance or resistance in wild $C$. реро could slightly increase fecundity under ZYMV pressure; however, the degree to which those genes improve fecundity and are under positive selection would depend on the particular resistance or tolerance genes and their expression against the novel genetic background of the wild plant. In the case of gene flow from CZW-3 into wild $C$. pepo, conventional crop resistance or tolerance would slightly improve fecundity, but would have less dramatic effects than the virusresistance transgene.

Successful introgression will depend on a confluence of several factors. Squash cultivar traits (e.g., bushy architecture and fewer seeds per plant) would likely lower the survival of first generation GE crop-wild hybrids and thus lower the rate of further transgenic gene flow into wild $C$. pepo populations, but by the third generation of gene flow, crop genes would not substan- 
tially prevent further introgression into wild $C$. реро. Wild $C$. pepo acting as weeds in agricultural fields may provide a transitional medium for transgene introgression, because the weed's agricultural habitat would be more amenable to the mixture of crop and wild morphology of the first couple of hybrid generations. Later generations could then more successfully mate with wild $C$. pepo in natural habitats. Transgene introgression into a wild $C$. pepo population under high virus pressure is unlikely due to lowered fecundity of diseased wild C. pepo (Fuchs et al. 2004b); however, if ZYMV (and likely CMV or WMV-2) infected a wild population after initial introgression, the likelihood of further transgene introgression into the wild population would increase, because virus-resistant hybrids would have higher fecundity than infected wild individuals. Due to the continued use of susceptible squash cultivars, agricultural fields might provide greater virus pressure than natural habitats and thereby increase selection for the transgene in hybrids growing in close proximity to agricultural activity.

\section{Implications for risk assessment of virus-resistant GE crops}

This study joins a number of recent studies (e.g., Bartsch et al. 2001, Burke and Rieseberg 2003, Snow et al. 2003) that together demonstrate a range of fitness effects associated with gene flow from GE pathogenresistant and herbivore-resistant crops into populations of wild relatives. The impact of GE virus resistance in wild plant populations is highly dependent on the likelihood of transgene introgression and the prevalence and fitness effect of the virus targeted by the transgene in the wild plant population. This emphasizes the importance of examining each of these factors (introgression likelihood, fitness impact of transgene in absence and presence of virus, virus incidence in wild populations) for each GE virus-resistant crop during its development and during the federal permitting process. It cannot be assumed that different crop plants engineered to resist different target viruses will have similar risk profiles.

Our study also provides insight into the similarities and disparities between conventional and transgenic crop-to-wild gene flow in terms of virus resistance. Here we show that gene flow from a conventional cultivar not specifically bred for virus resistance may potentially increase wild plant fecundity, but not as dramatically as gene flow from a plant engineered for virus resistance. This intriguing result warrants more research. Fundamentally, the mechanism by which conventional or transgenic crop genes can enter a population of wild relatives is the same, each with potential fitness impacts on the recipient population. We would expect that gene flow from conventionally bred crops with dominant, single locus virus resistance would pose risks similar to those posed by genetically engineered virus-resistant crops. Nonetheless, genetic engineering technology increases the potential of such impacts, because it can more strongly and directly target a pest than can most conventional breeding technologies. Entry of the engineered gene therefore poses greater potential to change the interaction between a wild relative and the targeted agricultural pest. The same direct targeting that makes genetic engineering so appealing as a crop improvement technology increases the potential impacts of crop-towild gene flow on wild plant populations.

\section{ACKNOWLEDGMENTS}

We thank G. K. Blaisdell for support in the laboratory and field; P. Cooper for greenhouse assistance; J. Crispell help with pollen quantification and field assistance; M. Jahn and G. Moriarty for their generous provision of virus inoculum; $F$. Vermeylen for statistical advice; and S. McKay, J. Finnerty, D. Van Vleet, and their staffs for their excellent agricultural services. M. Geber, P. Marks, A. Agrawal, and S. Murphy provided critical comments on the manuscript. This research was supported by Sigma Xi Grants-in-Aid of Research (to K. D. Laughlin), the Andrew W. Mellon Foundation (to K. D. Laughlin), Cornell University Sigma Xi (to K. D. Laughlin), Cornell University (to A. G. Power and K. D. Laughlin), NSF DEB-0407610 (to A. G. Power and K. D. Laughlin), and NSF DEB-0444639 (to A. G. Power).

\section{Literature Cited}

Accord, B. R. 1996. Asgrow Seed Co.; availability of determination of nonregulated status for a squash line genetically engineered for virus resistance. Federal Register 61:33484-33485.

Andow, D. A., and C. Zwahlen. 2006. Assessing environmental risks of transgenic plants. Ecology Letters 9:196-214.

Antonovics, J. 1999. Pathogens and plant populations dynamics: the effects of resistance genes on numbers and distribution. Pages 49-55 in P. M. Traynor and H. H. Westwood, editors. Ecological effects of pest resistance genes in managed ecosystems. Information Systems for Biotechnology, Blacksburg, Virginia, USA.

Antonovics, J., P. H. Thrall, and A. M. Jarosz. 1997. Genetics and the spatial ecology of species interactions: the SileneUstilago system. Pages 158-180 in D. Tilman and P. Kareiva, editors. Spatial ecology: the role of space in population dynamics and interspecific interactions. Princeton University Press, Princeton, New Jersey, USA.

APHIS/USDA (Animal and Plant Health Inspection Service/U.S. Department of Agriculture). 1994. Availability of determination of nonregulated status for virus resistant squash. Federal Register 59(238)64187-64189.

Bartsch, D., U. Brand, C. Morak, M. Pohl-Orf, I. Schuphan, and N. C. Ellstrand. 2001. Biosafety of hybrids between transgenic virus-resistant sugar beet and Swiss chard. Ecological Applications 11:142-147.

Burke, J. M., and L. H. Rieseberg. 2003. Fitness effects of transgenic disease resistance in sunflowers. Science 300:1250.

Catherall, P. 1966. Effects of barley yellow dwarf virus on the growth and yield of single plants and simulated swards of perennial rye-grass. Annals of Applied Biology 57:155.

Catherall, P., and E. Griffiths. 1966. Influence of cocksfoot streak virus on growth of single cocksfoot plants. Annals of Applied Biology 57:141.

Cowan, C. W., and B. D. Smith. 1993. New perspectives on a wild gourd in eastern North America. Journal of Ethnobotany $13: 17-54$.

Decker-Walters, D. S., J. E. Staub, S. M. Chung, E. Nakata, and H. D. Quemada. 2002. Diversity in free-living populations of Cucurbita pepo (Cucurbitaceae) as assessed by random amplified polymorphic DNA. Systematic Botany 27:19-28. 
Decker-Walters, D. S., T. W. Walters, C. W. Cowan, and B. D. Smith. 1993. Isozymic characterization of wild populations of Cucurbita pepo. Journal of Ethnobotany 13:55-72.

Desbiez, C., and H. Lecoq. 1997. Zucchini yellow mosaic virus. Plant Pathology 46:809-829.

Diaz-Pendon, J. A., V. Truniger, C. Nieto, J. Garcia-Mas, A. Bendahmane, and M. A. Aranda. 2004. Advances in understanding recessive resistance to plant viruses. Molecular Plant Pathology 5:223-233.

Ellstrand, N. C. 2003a. Current knowledge of gene flow in plants: implications for transgene flow. Philosophical Transactions of the Royal Society B 358:1163-1170.

Ellstrand, N. C. 2003b. Dangerous liaisons: when crops mate with their wild relatives. Johns Hopkins University Press, Baltimore, Maryland, USA.

Ellstrand, N. C., and C. A. Hoffman. 1990. Hybridization as an avenue of escape for engineered genes: strategies for risk reduction. BioScience 40:438-442.

Friess, N., and J. Maillet. 1996. Influence of cucumber mosaic virus infection on the intraspecific competitive ability and fitness of purslane (Portulaca oleracea). New Phytologist 132: 103-111.

Friess, N., and J. Maillet. 1997. Influence of cucumber mosaic virus infection on the competitive ability and reproduction of chickweed (Stellaria media). New Phytologist 135:667-674.

Fuchs, M., E. M. Chirco, and D. Gonsalves. 2004a. Movement of coat protein genes from a commercial virus-resistant transgenic squash into a wild relative. Environmental Biosafety Research 3:5-16.

Fuchs, M., E. M. Chirco, J. R. McFerson, and D. Gonsalves. 2004b. Comparative fitness of a wild squash species and three generations of hybrids between wild $\times$ virus-resistant transgenic squash. Environmental Biosafety Research 3:17-28.

Fuchs, M., D. M. Tricoli, K. J. Carney, M. Schesser, J. R. McFerson, and D. Gonsalves. 1998. Comparative virus resistance and fruit yield of transgenic squash with single and multiple coat protein genes. Plant Disease 82:1350-1356.

Funayama, S., K. Hikosaka, and T. Yahara. 1997. Effects of virus infection and growth irradiance on fitness components and photosynthetic properties of Eupatorium makinoi (Compositae). American Journal of Botany 84:823-829.

Hander, C. A., P. J. McLeod, and H. A. Scott. 1993. Incidence of aphids (Homoptera, Aphididae) and associated potyviruses in summer squash in Arkansas. Journal of Entomological Science 28:73-81.

Khetarpal, R., B. Maisonneuve, and Y. Maury. 1998. Breeding for resistance to plant viruses. Pages $14-32$ in A. Hadidi, R. Khetarpal, and H. Koganezawa, editors. Plant virus disease control. APS, St. Paul, Minnesota, USA.

Kirkpatrick, K. J., and H. D. Wilson. 1988. Interspecific gene flow in Cucurbita: Cucurbita texana vs. Cucurbita pepo. American Journal of Botany 75:519-527.

Laughlin, K. D. 2006. Transgenic virus resistance, plant fitness and virus competition in wild squash (Cucurbita pepo). Dissertation. Cornell University, Ithaca, New York, USA.

Lecoq, H., C. Desbiez, C. Wipf-Scheibel, and M. Girard. 2003. Potential involvement of melon fruit in the long distance dissemination of cucurbit potyviruses. Plant Disease 87:955959.

MacClement, W., and M. Richards. 1956. Virus in wild plants. Canadian Journal of Botany 34:793.

Malmstrom, C. M., C. C. Hughes, L. A. Newton, and C. J. Stoner. 2005. Virus infection in remnant native bunchgrasses from invaded California grasslands. New Phytologist 168: 217-230.

Maskell, L. C., A. F. Raybould, J. I. Cooper, M. L. Edwards, and A. J. Gray. 1999. Effects of turnip mosaic virus and turnip yellow mosaic virus on the survival, growth and reproduction of wild cabbage (Brassica oleracea). Annals of Applied Biology 135:401-407.
Mcleod, P. J., H. A. Scott, and T. E. Morelock. 1986. Zucchini yellow mosaic virus: a new severe cucurbit disease. Arkansas Farm Research 35. Agricultural Experiment Station, Division of Agriculture, University of Arkansas, Fayetteville, Arkansas, USA.

Monteith, J. 1973. Principles of environmental physics. Edward Arnold, London, UK.

NRC. 2002. Environmental effects of transgenic plants: the scope and adequacy of regulation. National Academy Press, Washington, D.C., USA.

NRC. 2004. Biological confinement of genetically engineered organisms. National Academy Press, Washington, D.C., USA.

Oliver, L. R., S. R. Harrison, and M. McClelland. 1983. Germination of Texas gourd (Cucurbita texana) and its control in soybeans (Glycine maxi). Weed Science 31:700706.

Pilson, D., and H. R. Prendeville. 2004. Ecological effects of transgenic crops and the escape of transgenes into wild populations. Annual Review of Ecology, Evolution, and Systematics 35:149-174.

Power, A. G. 2002. Ecological risks of transgenic virus-resistant crops. Pages 125-142 in D. Letourneau and B. Burrows, editors. Genetically engineered organisms: assessing environmental and human health effects. CRC Press, New York, New York, USA.

Power, A. G., and C. E. Mitchell. 2004. Pathogen spillover in disease epidemics. American Naturalist 164:S79-S89.

Quemada, H., D. S. Decker-Walters, and J. E. Staub. 2002. Case study: gene flow from commercial transgenic Cucurbita pepo I to free-living C. pepo. Pages $71-78$ in Scientific Methods Workshop: Ecological and Agronomic Consequences of Gene Flow from Transgenic Crops to Wild Relatives, Columbus, Ohio, USA.

Quesada, M., K. Bollman, and A. G. Stephenson. 1995. Leaf damage decreases pollen production and hinders pollen performance in Cucurbita texana. Ecology 76:437-443.

Raybould, A. F., L. C. Maskell, M. L. Edwards, J. I. Cooper, and A. J. Gray. 1999. The prevalence and spatial distribution of viruses in natural populations of Brassica oleracea. New Phytologist 141:265-275.

SAS. 2003. MIXED procedure. SAS Institute, Cary, North Carolina, USA.

Snow, A. A., and P. M. Palma. 1997. Commercialization of transgenic plants: potential ecological risks. BioScience 47 : 86-96.

Snow, A. A., D. Pilson, L. H. Rieseberg, M. J. Paulsen, N. Pleskac, M. R. Reagon, D. E. Wolf, and S. M. Selbo. 2003. A $\mathrm{Bt}$ transgene reduces herbivory and enhances fecundity in wild sunflowers. Ecological Applications 13:279-286.

Spencer, L. J. 2001. Hybridization and introgression in Cucurbita pepo: an examination of transgenic virus resistance on wild-crop hybrids. Dissertation. Ohio State University, Columbus, Ohio, USA.

Spencer, L. J., and A. A. Snow. 2001. Fecundity of transgenic wild-crop hybrids of Cucurbita pepo (Cucurbitaceae): implications for crop-to-wild gene flow. Heredity 86:694-702.

Thresh, J. M. 1974. Temporal patterns of virus spread. Annual Review of Phytopathology 12:111-128.

Tricoli, D. M., K. J. Carney, P. F. Russell, J. R. McMaster, D. W. Groff, K. C. Hadden, P. T. Himmel, J. P. Hubbard, M. L. Boeshore, and H. D. Quemada. 1995. Field evaluation of transgenic squash containing single or multiple virus coat protein gene constructs for resistance to cucumber mosaic virus, watermelon mosaic virus 2 , and zucchini yellow mosaic virus. Nature Biotechnology 13:1458-1465.

Yahara, T., and K. Oyama. 1993. Effects of virus-infection on demographic traits of an agamospermous population of Eupatorium chinense (Asteraceae). Oecologia 96:310-315. 